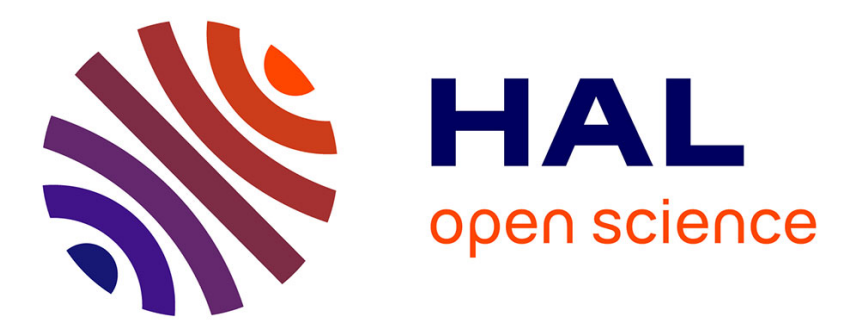

\title{
Microcrystalline silicon: Strain gauge and sensor arrays on flexible substrate for the measurement of high deformations
}

Y. Kervran, O. de Sagazan, S. Crand, N. Coulon, T. Mohammed-Brahim, O Brel

\section{To cite this version:}

Y. Kervran, O. de Sagazan, S. Crand, N. Coulon, T. Mohammed-Brahim, et al.. Microcrystalline silicon: Strain gauge and sensor arrays on flexible substrate for the measurement of high deformations. Sensors and Actuators A: Physical , 2015, 236, pp.273-280. 10.1016/j.sna.2015.08.001 . hal-01240765

HAL Id: hal-01240765

https://hal-univ-rennes1.archives-ouvertes.fr/hal-01240765

Submitted on 27 Jan 2016

HAL is a multi-disciplinary open access archive for the deposit and dissemination of scientific research documents, whether they are published or not. The documents may come from teaching and research institutions in France or abroad, or from public or private research centers.
L'archive ouverte pluridisciplinaire HAL, est destinée au dépôt et à la diffusion de documents scientifiques de niveau recherche, publiés ou non, émanant des établissements d'enseignement et de recherche français ou étrangers, des laboratoires publics ou privés. 


\title{
Microcrystalline silicon: strain gauge and sensor arrays on flexible substrate for the measurement of high deformations
}

\author{
Y. Kervran ${ }^{\mathrm{a}, \mathrm{b}}$ *, O. De Sagazan ${ }^{\mathrm{a}}$, S. Crand ${ }^{\mathrm{a}}$, N. Coulon ${ }^{\mathrm{a}}$, T. Mohammed-Brahim ${ }^{\mathrm{a}}$, O. Brel ${ }^{\mathrm{b}}$ \\ a DMM-IETR UMR-CNRS 6164, Université de RENNES 1, 35042 Rennes Cedex, FRANCE \\ b ODAXOS SA, Maison de la technopole, 53000 Laval, FRANCE \\ Corresponding author: \\ $+33223236585$ \\ yannick.kervran@univ-rennes1.fr
}

\begin{abstract}
This paper presents strain sensor arrays on flexible substrates able to measure local deformation induced by radii of curvature of few millimeters. Sensors use $n$-type doped microcrystalline silicon ( $\mu \mathrm{c}-\mathrm{Si}$ ) as piezoresistive material, directly deposited on polyimide sheets at $165^{\circ} \mathrm{C}$. Sensitivity of individual sensors was investigated under tensile and compressive bending at various radii of curvature, down to $5 \mathrm{~mm}$. A Transmission Line Method was used to extract the resistivity for each radius. The devices exhibited longitudinal gauge factors of 31 and longitudinal piezoresistive coefficients of $-4.10^{-10} \mathrm{~Pa}^{-1}$. Reliability was demonstrated with almost unchanged resistances after cycles of bending (standard deviation of $1.7 \%$ ). Strain gauge arrays, composed of 800 resistors on a $2 \mathrm{~cm}^{2}$ area, were fabricated with a spatial resolution of $500 \times 500 \mu \mathrm{m}^{2}$. Strain mapping showed the possibility to detect local deformation on a single resistor or to detect larger objects. These strain sensor arrays can find applications when high sensitivity and high spatial resolution is required. This paper also showed that $\mu \mathrm{c}-\mathrm{Si}$ can be a relevant semi-conductor candidate for flexible electronics.
\end{abstract}

Keywords: Microcrystalline silicon, strain gauge arrays, high spatial resolution arrays, flexible substrate

Microcrystalline Si strain gauge on plastic under compressive and tensile bending Average gauge factor of 31 and good mechanical reliability

High density strain gauge matrix $\left(0.25 \mathrm{~mm}^{2}\right.$ resolution) tested under pressure

Good spatial localization of an applied pressure

Shape detection of any object

\section{Introduction}

Flexible electronics becomes a major research domain due to a fast growing market. Many devices on flexible substrates are under development with great possibilities in robotics [1], health monitoring [2], epidermal electronics [3], intelligent textile [4] or aeronautics [5]. Resistive-based tactile sensors are often preferred thanks to a basic working principle and have been widely reported $[6,7]$. However, most present ones are limited at high deformations induced by low radius of curvature (few millimeters). This limitation is even more important when high spatial resolution is required. The purpose of this work is to develop strain sensor arrays on flexible substrate which could measure local deformations, with spatial resolution in the range of $100 \times 100$ to $500 \times 500$ $\mu \mathrm{m}^{2}$. According to the literature, such arrays have not been previously developed.

Two main types of materials are used as strain gauges: metals and semiconductors. Other materials such as organic semi-conductors [8], graphite [9], carbon nanotubes [10] or conductive polymer composites [11] are approached in the literature but are still not matured. The gauge factor $(G F)$ is typically used to quantify the sensitivity of a resistive strain sensor and is defined by Eq. (1) as the ratio of the relative change in its resistance $\left(\Delta R / R_{0}\right)$ and the strain $\varepsilon$ applied to that sensor:

$G F=\frac{\Delta R / R_{0}}{\varepsilon}$

For metals, $G F$ is low, between 2 to 5 [12]. In addition, their low resistivity implies long wires to obtain measurable values, which is a huge limitation to reach the expected spatial resolution. For semiconductors, such 
as silicon-based materials, $G F$ exhibits much larger values thanks to the so-called piezoresistivity effect: 100 for single crystalline silicon ( $\mathrm{sc-Si}$ ), 20-40 for polycrystalline silicon (poly-Si) [13] or 20-30 for amorphous silicon (a-Si) [14]. The possibility to control their resistivity with doping is also an advantage when designing measurable resistor in limited spaces.

Flexible sensor arrays based on single crystalline silicon have been reported in the literature $[4,15,16,17]$. Silicon material can be embedded in soft polymers or reported on a flexible substrate. However, due to the mechanically brittle nature of silicon, it cannot be bent down to few millimeters. Transfer techniques exist to obtain bendable ultrathin silicon (30-50 $\mu \mathrm{m}$ thick) but suffer from several drawbacks including (i) high costs; (ii) low efficiencies; and (iii) required additional elements like adhesive at silicon/substrate interface implying possible complex behaviours.

Another approach aims to overcome these limitations through the use of deposited silicon thin-films directly on plastic, with low temperature process techniques $\left(100-250^{\circ} \mathrm{C}\right)$. Silicon films can be amorphous or polycrystalline with grain size of $10-100 \mathrm{~nm}$. Nano- or micro-crystalline silicon (respectively nc-Si, $\mu \mathrm{c}-\mathrm{Si}$ ), is much more electrically stable than amorphous silicon and present the possibility to change its resistivity in a larger range. Flexible strain sensors using a-Si, $\mu \mathrm{c}-\mathrm{Si}$ and nc-Si have been already studied $[14,18,19,20,21,22]$.

Nevertheless, this work presents results for higher bending radii of curvature $(5 \mathrm{~mm})$ to confirm the potential of $\mu \mathrm{c}-\mathrm{Si}$ in flexible electronics.

Thus, this paper reports a large area, high sensitivity and high spatial resolution strain gauge arrays using directly deposited $\mu \mathrm{c}-\mathrm{Si}$ film as piezoresistive material. Strain gauges are first investigated individually with compressive and tensile tests. A Transmission Line Method was used to extrapolate directly the resistivity of $\mu \mathrm{c}-\mathrm{Si}$ films.

These gauges are then integrated into high density arrays ( 800 sensors on a $2 \mathrm{~cm}^{2}$ area, i.e. a spatial resolution of $250 \mu \mathrm{m}^{2}$ ) and characterized with a custom acquisition system. The technology is realized on Kapton substrates with various thicknesses $(25,50,125 \mu \mathrm{m})$ to show the large capabilities.

\section{Microcrystalline silicon film}

PECVD is a usual method to obtain as-deposited crystallized silicon films at low temperature with carrier gases such as silane $\left(\mathrm{SiH}_{4}\right)$ and hydrogen $\left(\mathrm{H}_{2}\right)$, preferentially with very high dilution of silane in hydrogen (less than $1 \%$ ) [23]. It was shown previously using Raman spectroscopy that argon (Ar) added in the gas mixture increases the dissociation of $\mathrm{SiH}_{4}$, producing high $\mathrm{H}_{2}$ atomic content and, as a consequence, higher crystalline fraction [24]. The Transverse Optic band (TO) of the Raman spectrum is located around $480 \mathrm{~cm}^{-1}$ for a-Si and at $520 \mathrm{~cm}^{-}$ ${ }^{1}$ for sc-Si. Fig. 1 shows the Raman TO band obtained for $50 \mathrm{~nm}$ thick films deposited at $165^{\circ} \mathrm{C}$ by RF-PECVD using (i) $1.5 \mathrm{sccm}$ of $\mathrm{SiH}_{4}$ and $150 \mathrm{sccm}$ of $\mathrm{H}_{2}$ (1\% dilution of $\mathrm{SiH}_{4}$ in $\mathrm{H}_{2}$, red dash plot) and (ii) $1.5 \mathrm{sccm}$ of $\mathrm{SiH}_{4}, 75 \mathrm{sccm}$ of $\mathrm{H}_{2}$ and $75 \mathrm{sccm}$ of $\mathrm{Ar}$ ( $1 \%$ dilution of $\mathrm{SiH}_{4}$ in $\mathrm{Ar}-\mathrm{H}_{2}$ mixture, black solid plot). Obviously, the first film (i) is mainly amorphous whereas the second one (ii) is mainly crystallized with respective calculated crystalline fractions of $20 \%$ and $60 \%$.

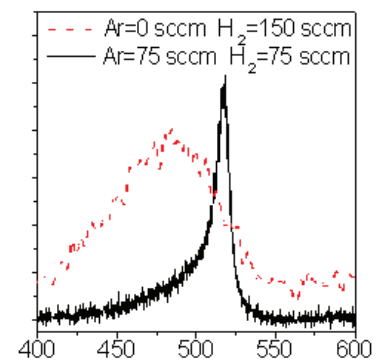

Fig. 1. Raman TO band obtained for a $50 \mathrm{~nm}$ thick $\mu \mathrm{c}-\mathrm{Si}$ films deposited without (red dash plot) and with (black solid plot) Ar in the deposition gas mixture. Amorphous contribution $\left(480 \mathrm{~cm}^{-1}\right)$ is dominant in "without argon" film. Crystalline phase $\left(520 \mathrm{~cm}^{-1}\right)$ is dominant in "with argon" film.

To obtain $n$-type doped $\mu \mathrm{c}$-Si films, arsine $\left(\mathrm{AsH}_{3}\right)$ is added to the gas mixture as dopant. The electrical conductivity at ambient temperature varies in a very large range depending on the $\mathrm{AsH}_{3}$ flow: from $3.10^{-9} \mathrm{~S}_{\mathrm{cm}} \mathrm{cm}^{-1}$ to $12{\mathrm{~S} . \mathrm{cm}^{-1}}^{-}$for a $50 \mathrm{~nm}$ thick $\mu \mathrm{c}$-Si film, respectively undoped and highly n-type doped. $P$-type doped $\mu \mathrm{c}-\mathrm{Si}$ films were also deposited by adding diborane $\left(\mathrm{B}_{2} \mathrm{H}_{6}\right)$ to the gas mixture as dopant. The minimum conductivity obtained with the highest doping was only $1{\mathrm{~S} . \mathrm{cm}^{-1}}^{-1}$. According to the spatial resolution aimed, the resistor dimensions required can be an area of $100 \times 100 \mu \mathrm{m}^{2}$. In this work, n-type doped $\mu \mathrm{c}-\mathrm{Si}$ is used with a thickness in the range of $50-100 \mathrm{~nm}$ to obtain resistances from 10 to $50 \mathrm{k} \Omega$, compatible to our acquisition system. 


\section{Strain gauges}

\subsection{Design and fabrication process}

The structure is based on a Transmission Line Method (TLM). The aim is to measure the resistivity of a semiconductor film and the contact resistance $R_{C}$ at the semi-conductor/metal contact interface. Indeed, considering $R_{T}$ as the total measured resistance, $R_{T}=\rho L /(\mathrm{eW})+2 R_{C}+R_{\text {routing }}$ where $\rho$ is the resistivity of the semi-conductor ( $\mu \mathrm{c}-\mathrm{Si}$ ), $L, W$ and $e$ are respectively length, width and thickness of the resistor. The routing resistance $R_{\text {routing }}$, made of aluminum (Al), can be neglected compared the semi-conductor resistance. Then, if contacts are ohmic, the fit of $R_{T}$ versus $L$ should be linear with a slope proportional to the resistivity $\rho$. The contact resistance $R_{C}$ is also determined from the intercept of linear fit with the $R_{T}$-axis.

In our case, the purpose is to measure the resistivity for several radii of curvature to quantify the sensitivity of the $\mu \mathrm{c}-\mathrm{Si}$ film as a strain sensor. As stated previously, using the general equation for a resistance $R=\rho L /(\mathrm{eW})$ one is then able to obtain $\Delta R / R=\Delta \rho / \rho+\Delta L / L(1+2 v)$, where $v$ is the Poisson's ratio of the resistor material. The second term $\Delta L / L(1+2 v)$ denotes the geometrical effect during bending. The first term $\Delta \rho / \rho$ is the relative resistivity variation and denotes the piezoresistive effect. For a material, such as polycristalline silicon, it is defined as $\Delta \rho / \rho=\pi_{L} \sigma_{L}+\pi_{T} \sigma_{T}$, where $\pi_{L}, \pi_{T}$ are the longitudinal and transversal piezoresistive coefficients of poly-Si respectively and $\sigma_{L}, \sigma_{T}$ are the longitudinal and transversal applied stresses respectively. Thus, by extracting directly the resistivity $\rho$ for each radius and study as well $\Delta \rho / \rho$, the piezoresistive coefficients can be deduced. In this study, we focus on the longitudinal sensitivity.

The fabrication process begins with a cleaning step of a $5 \times 5 \mathrm{~cm}^{2}$ large and $50 \mu \mathrm{m}$ thick polyimide (PI) substrate using acetone, alcohol and deionized water. The sheet is then coated on one side with a $50 \mathrm{~nm}$ thick silicon nitride passivation layer $\left(\mathrm{SiN}_{\mathrm{x}}\right)$ deposited by RF-PECVD at $150^{\circ} \mathrm{C}$ using a $\mathrm{SiH}_{4} / \mathrm{NH}_{3}$ mixture. The active layer, a $100 \mathrm{~nm}$ thick $n$-type arsenic doped $\mu \mathrm{c}$-Si film, is deposited following the conditions described in paragraph 2 and islands-like structures are patterned by Reactive Ion Etching (RIE) using $\mathrm{SF}_{6}$ plasma. A $100 \mathrm{~nm}$ thick aluminum layer $(\mathrm{Al})$ is deposited by thermal evaporation and patterned by wet etching to form electrodes. The sample is finally annealed in $\mathrm{N}_{2}$ atmosphere at $180^{\circ} \mathrm{C}$ for $2 \mathrm{~h}$. Fig. 2 provides an optical image of a final sample and a schematic illustration of a TLM structure.

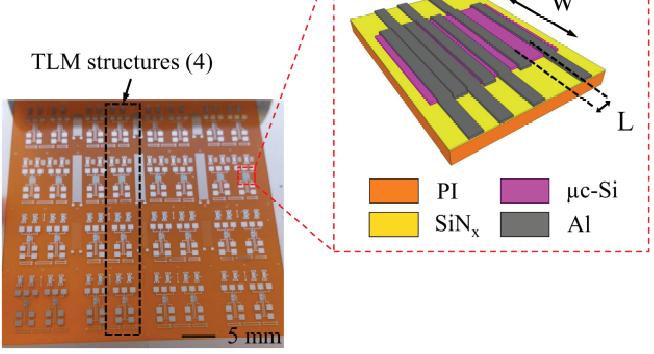

Fig. 2. (a) Optical image of a sample, (b) Schematic illustration of a final TLM structure. Each TLM pattern is composed of 6 resistors, with different lengths $L(5,10,20,40,80$ and $160 \mu \mathrm{m}) .4$ widths $W$ are studied (1000, $500,250$ and $125 \mu \mathrm{m})$, which results in 24 distinct resistors.

\subsection{Bending set-up and test procedure}

In order to quantify the piezoresistive effect, strain gauges are measured with different radii of curvature $r$. Several methods are commonly used and can be separated in 2 categories: dynamic and static bending tests. Dynamic measurements may provide more informative results but require sophisticated instruments such as custom ones or 4-point bending tests [20]. Moreover, the classical 4-point method does not allow high bending. Static tools are easier to handle but measurements can be difficult for thin plastic substrates and low radii of curvature $(r \leq 5 \mathrm{~mm})$. In our case, a 2-wire static I-V method is used.

For each radius, 4 TLM structures are measured. These 4 structures correspond to one column on the sample (see Fig. 2) and are placed on the same bending axis. Fig. 3 shows the homemade tools used to apply tensile and 
compressive stresses: 5 tensile $(2.5,2,1.5,1,0.5 \mathrm{~cm})$ and 4 compressive radii of curvature $(2.5,2,1.5,1 \mathrm{~cm})$ were used.

I-V measurements are performed by an Agilent B1500A at room temperature, with applied voltage between \pm 1 $\mathrm{V}$. The procedure consists in a first measurement without bending (flat substrate) to obtain the initial values. The sample is then fixed onto the tensile bending tools from the lowest curvature (highest radius) to the highest curvature (lowest radius). Between each bending, resistors are reflattened and measured to evaluate reliability. The same procedure is made for compressive tests. Since the study focus on the longitudinal sensitivity, resistors are placed so that the current flow in the channel is in the same direction of the curvature.

(b)

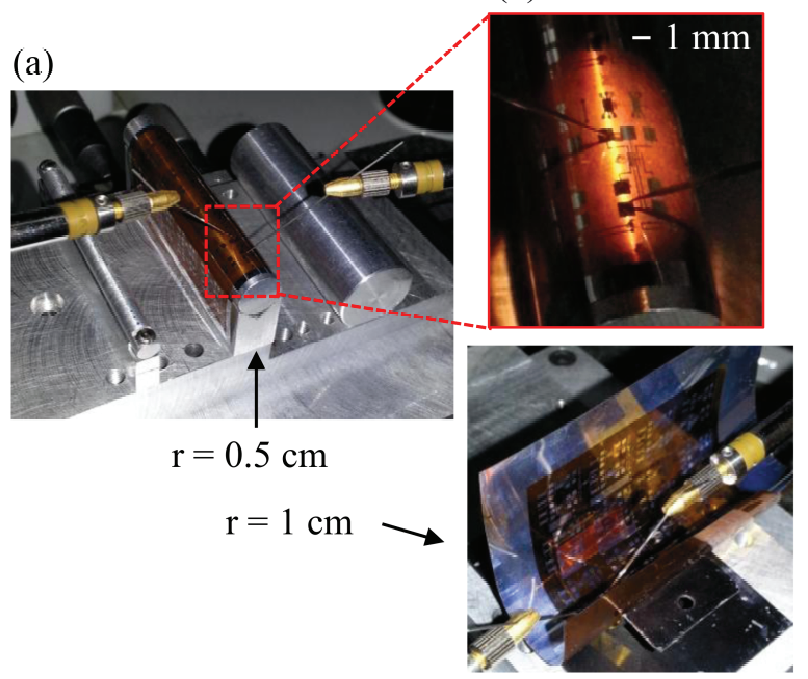

(c)

Fig. 3. Set-up used for I-V measurements during bending: (a) and (b) tensile tests, (c) compressive tests.

\subsection{Strain Calculation}

For each radius of curvature, the strain $\varepsilon$ applied to the structure is calculated using a bi-layer simplified model of the real tri-layer structure with respect to their Young modulus $Y$ and thickness values [25], Fig. 4. In our case, the material properties are presented in Table 1. This model takes into account the substrate and the stiffest layer, which mainly define the mechanical behavior of the device. Electrodes are not represented since we focus on the resistor, between the 2 contacts. The bi-layer model is thus constituted by the PI substrate and the $\mathrm{SiN}_{\mathrm{x}}$ layer.

\begin{tabular}{|l|l|l|l|}
\hline Layer & PI & $\mathrm{SiN}_{\mathrm{x}}$ & $\mu \mathrm{c}-\mathrm{Si}$ \\
\hline Thickness & $50 \mu \mathrm{m}$ & $50 \mathrm{~nm}$ & $100 \mathrm{~nm}$ \\
\hline$Y(\mathrm{GPa})$ & $2.5[26]$ & $183[25]$ & $80[27]$ \\
\hline
\end{tabular}

Table 1. Material properties used in this paper.

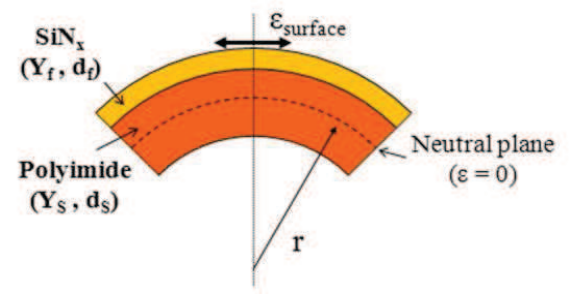


Fig. 4. Schematic cross-section of the mechanical model. The names refer to Eq. (2).

The longitudinal strain $\varepsilon_{\text {surface }}$ on the surface of the layer is given by the equation derived from [25]:

$\varepsilon_{\text {surface }}=\left(\frac{1}{r} \pm \frac{1}{r_{0}}\right)\left(\frac{d_{s}+d_{f}}{2}\right) \frac{1+2 \eta+\chi \eta^{2}}{(1+\eta)(1+\chi \eta)}(2)$

where $r$ and $r_{0}$ are the applied and initial radii of curvature respectively, $d_{S}$ and $d_{f}$ are substrate and layer thicknesses respectively, $\chi$ and $\eta$ are defined by $\chi=Y_{f} / Y_{S}$ and $\eta=d_{f} / d_{S}$, where $Y_{S}$ and $Y_{f}$ are substrate and layer Young modulii respectively. The plus (or minus) signs depends on applied bending opposite to (or with) the built-in curvature. After the fabrication process, the samples have a low tensile built-in curvature $r_{0}$ of $\sim 18 \mathrm{~cm}$. This initial curvature is due to the thermal steps in the fabrication procedure. Polymeric substrates have indeed coefficient of thermal expansion (CTE) larger than those of inorganic materials. Consequently, residual strains (also called as thermal mismatch) can appear in the system, causing the sample to distort into a cylindrical shape. This behaviour has already been reported and is still investigated due to the wide variety of materials in flexible electronics [28], [29]. In our case, this low curvature is not a critical issue when handling the substrate. However, during flat position measurements, the latter is kept flat with adhesive tapes. This forced position implies a slight compressive strain in the film and the real no-strain position $\Delta \rho / \rho(\varepsilon=0)=0$ shifts toward compressive direction (see Fig. 7).

\subsection{Results}

\subsubsection{TLM measurements}

Fig. 5 shows the resistances measured for the 4 TLM structures presented on Fig. 2. Resistivity and contact resistance are extracted from the fits for each structure and values summarized in Table 2.Correlation coefficient of the linear fits are given in the figure and show the excellent linearity of the data. The mean resistivity of the $\mu \mathrm{c}-\mathrm{Si}$ film is $\rho=0.135 \pm 0.012 \Omega . \mathrm{cm}$, which is the value targeted with the deposition conditions. The resistivity variation can be explained by two main reasons: (i) the substrate can be slightly curved during the deposition of the $\mu \mathrm{c}$-Si film since the substrate is positioned manually and not reported on a rigid carrier; (ii) a high surface roughness on the Kapton substrate for large area $\left(\approx 100 \times 100 \mu \mathrm{m}^{2}\right)$ due to defaults on the surface. The contact resistance $R_{C}$, as determined from the intercept of linear fit, is negligible compared with the semi-conductor resistances. It results in a good ohmic contact between aluminium and $\mu \mathrm{c}-\mathrm{Si}$.

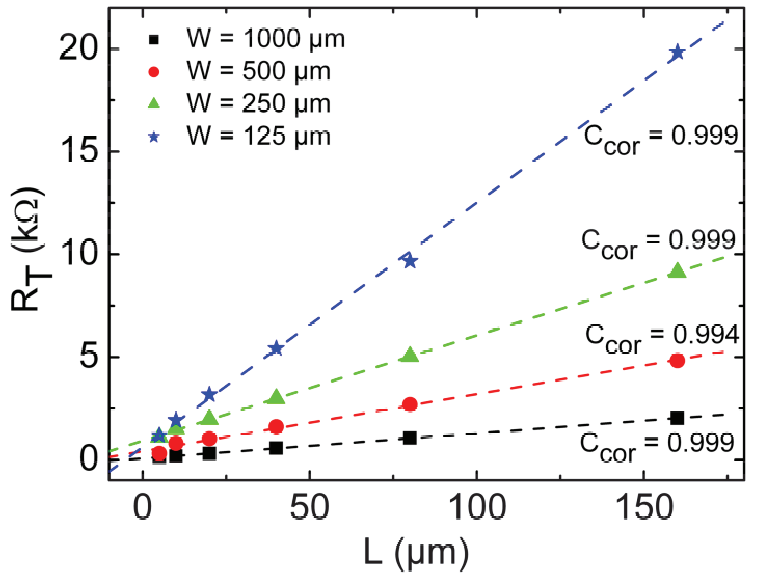

Fig. 5. Resistance $R_{T}$ measured as function of length $L$. Results are presented for 4 widths $W$. Correlation coefficients are named $C_{\text {corr }}$ to avoid any misunderstood.

\begin{tabular}{|l|l|l|l|l|}
\hline$W(\mu \mathrm{m})$ & 125 & 250 & 500 & 1000 \\
\hline$\rho(\Omega . \mathrm{cm})$ & 0.149 & 0.128 & 0.139 & 0.122 \\
\hline$R_{C}(\Omega)$ & 312 & 464 & 207 & 33 \\
\hline
\end{tabular}


Table 2. Electrical properties extracted from Fig. 3.

\subsubsection{Reflattened reliability}

For sensing applications, the ability to return to the initial value is essential. Thereby, we measured the resistances after every bending to observe possible changes after several cycles of bending to various radii. Fig. 6 shows example of resistances measured initially and after 8 following bending for one TLM structure (width $W$ $=1000 \mu \mathrm{m})$. Values are nearly the same even after a maximum bending of $5 \mathrm{~mm}$ and the mean standard deviation is $1.7 \%$. Same behaviours were observed for the 3 other TLM structures and no failure was observed for the 24 resistors (neither delamination nor cracks). Resistivity of the 4 structures also stays nearly unchanged, which can be seen in Table 3 showing the average value after every bending with very small standard deviations.

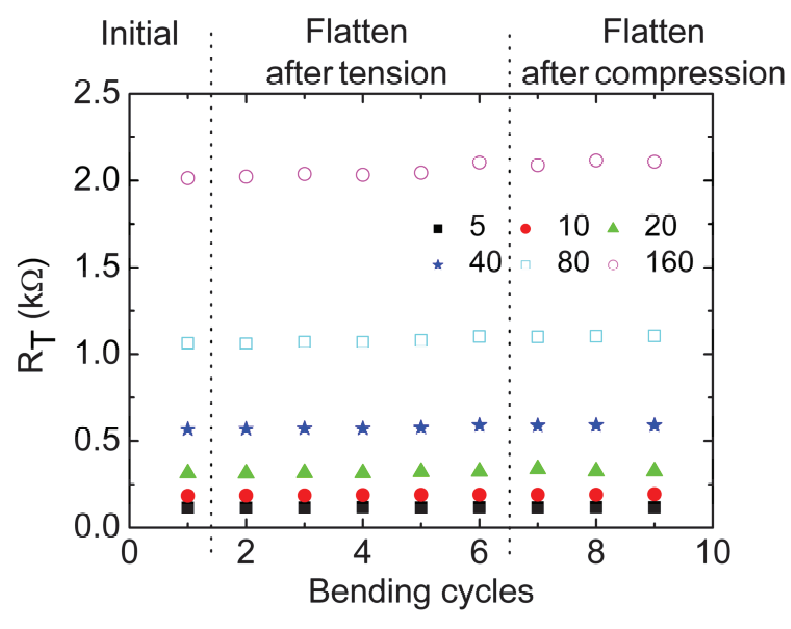

Fig. 6. Electrical stability of the sample when reflattened for $W=1000 \mu \mathrm{m}$ : resistances $R_{T}$ measured initially for a flat substrate (1) and after each bending (2 to 9).

\begin{tabular}{|l|l|l|l|l|}
\hline$W(\mu \mathrm{m})$ & 125 & 250 & 500 & 1000 \\
\hline$\rho(\Omega . \mathrm{cm})$ & $0.153 \pm 0.003$ & $0.131 \pm 0.002$ & $0.143 \pm 0.003$ & $0.125 \pm 0.003$ \\
\hline
\end{tabular}

Table 3. Average resistivity $\rho$ measured after every bending for the 4 TLM structures, with their respective standard deviation.

\subsubsection{Gauge Factor}

As explain previously, the strain is calculated using Eq. (2). Fig. 7 shows the relative resistivity variation $\Delta \rho / \rho$ as

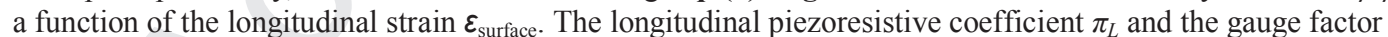
$G F$, defined previously, can be extracted from the linear fits. Each point is the mean value for the 4 widths $W$. The small standard deviations associated suggest no relevant influence of the resistivity on the sensitivity. This is important information in order to integrate those sensors in large area arrays. The behaviour appears to be different for tensile and compressive stresses resulting in 2 different gauge factors: $G F_{\text {Tens }} \sim-28$ and $G F_{\text {Comp }} \sim$ 37.5 respectively (variation of $30 \%$ ). This difference was already observed for $n$-type $\mu \mathrm{c}$-Si in [21], where authors suggested the apparition of micro-cracks that get more open (tensile) or closed (compressive). However, bending tests have been realized here in two orders: tensile (compressive) tests first followed by compressive (tensile) tests and in both case the same phenomenon appears.

On the other hand, if tensile and compressive data are considered together, we can conclude to an average $G F \sim$ 31. In both case, these $G F$ values are typical for $n$-type $\mu \mathrm{c}$-Si at low temperature obtained on various plastics and various thicknesses [19, 20, 21] or on Si-wafer [22]. It is slightly lower than sc-Si resistors bonded on PI substrate (-43) [15] but here, the present results are given for lower radius of curvature down to $5 \mathrm{~mm}$, instead of $12 \mathrm{~mm}$. No failure among the 24 resistors was observed, even down to $r=5 \mathrm{~mm}$ corresponding to an applied strain of $\varepsilon=0.47 \%$. 
In term of piezoresistance, our $\mu \mathrm{c}-\mathrm{Si}$ film presents an average longitudinal piezoresistive coefficient of $\sim-4.10^{-10}$ $\mathrm{Pa}^{-1}$. Such value is in the same order of those obtained for poly-Si deposited at high temperature and nc-Si deposited at the same range of temperature $[13,27]$.

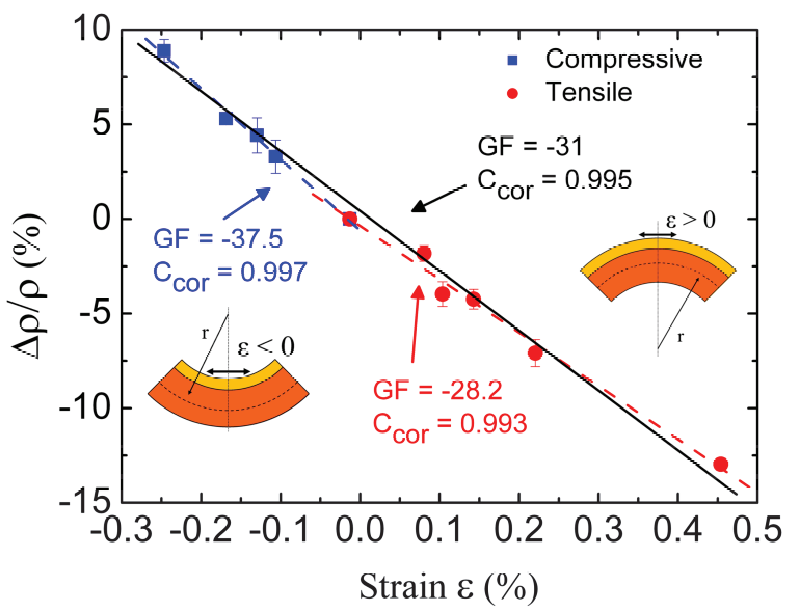

Fig. 7. Relative resistivity Variation $\Delta \rho / \rho$ vs. applied strain $\varepsilon$ (tensile strains, red data and negative strains, blue data). $C_{c o r}$ represent the correlation coefficient of the fits.

\section{Application: strain gauge arrays}

Similar $\mu \mathrm{c}-\mathrm{Si}$ strain gauges have been integrated in 800 element arrays ( 40 rows, 20 columns) in a $2 \mathrm{~cm}^{2}$ area with a spatial resolution of $500 \times 500 \mu \mathrm{m}^{2}$ (i.e. a pitch of $500 \mu \mathrm{m}$ ), Fig 8 . The aim is to use the flexible and stretchable ability of a plastic substrate associated with a piezoresistive material to localise and measure any deformation applied on the active area. The same design was processed on 3 Kapton substrates using different thicknesses commercially available: 25,50 and $125 \mu \mathrm{m}$. The fabrication process is slightly different from the previous TLM structure: a $200 \mathrm{~nm}$ thick SiN passivation layer instead of $50 \mathrm{~nm}$. Aluminum is used for electrodes and silicon dioxide $\left(\mathrm{SiO}_{2}\right)$ as dielectric material between the 2 metal layers (row and column layers).

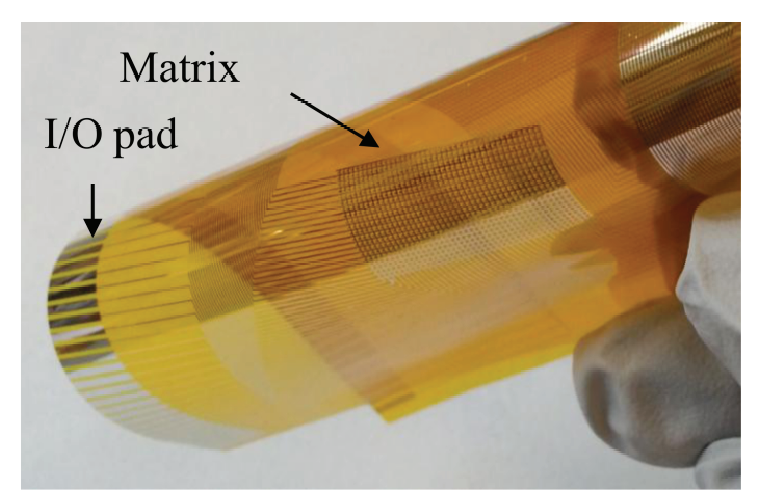

Fig. 8. Photography of a strain gauges array on a $25 \mu \mathrm{m}$ Kapton substrate ( 800 elements). The 60 Inputs/Outputs are on the edge of the substrate to be connected with Zero Insertion Force connector (ZIF).

\subsection{Multiplexing technology}

Most common techniques to measure resistance changes are based either on 4-wire method or Wheatstone Bridges. However, these techniques are not suitable for high density sensor arrays and for embedded systems which require limited spaces for electrode pads. For a passive matrix, without switching elements, a 2-wire technique associated with an external addressing system is preferred. Several scanning methods are reviewed in [30]. Here, the measurement is made one-by-one by applying an input voltage $V_{I N}$ between one column and one 
row to address a sensor pixel. The other rows and columns are connected to a zero voltage so the current only goes through the desired resistor. Current is then converted into voltage using a typical current-voltage converter with a $0-10 \mathrm{~V}$ output. Finally, the signal is converted to digital by a 10 bits analog-digital converter (ADC). Fig. 9 (a) shows a schematic of the readout circuit and Fig. 9 (b) shows a block diagram of the acquisition system. The output voltage $V_{O U T}$ of the equivalent circuit is defined by Eq. (3), where $R_{V}$ is a variable resistor and $R_{\mu c S i}$ the $\mu \mathrm{c}$-Si resistance of the measured sensor.

$$
V_{\text {OUT }}=-\frac{R_{V}}{R_{\mu c-S i}} V_{I N}
$$

A low-power Atmel 8-bit AVR RISC-based microcontroller drives the communication from the computer to the custom data acquisition hardware and also addresses the matrix. A strain measurement consists in a first scan of the array without stress and a second scan under stress. The relative resistance variation $\Delta R / R$ of every sensor is then calculated and a pressure mapping can be displayed.
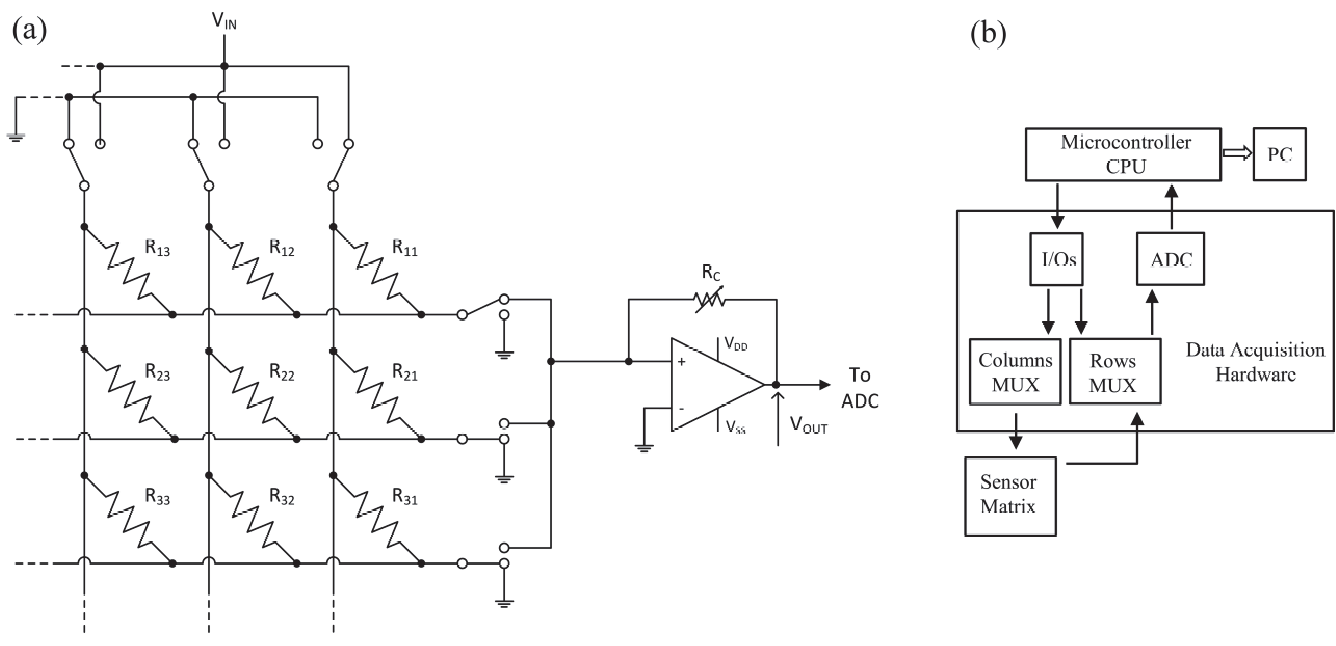

Fig. 9. (a) Readout circuit schematic. Here, only a $3 \times 3$ example array is presented and $R_{11}$ is measured, (b) Block diagram of the data acquisition method.

\subsection{Pressure localisation}

Various tests have been realized to observe the devices response under deformation. Static pressures were applied using a lever-system with additional weights sliding on the lever, shown in Fig. 10. The tip of the probe is spherical with a diameter of $\sim 2.4 \mathrm{~mm}$ and a contact surface of $\sim 1 \mathrm{~mm}$. A soft paper is placed under the device to allow its deformation. When the device is directly placed on a rigid platform such as steel or glass, no significant variations appear because the substrate alone is too stiff. In practical applications, a soft material like polydimethylsiloxane (PDMS) with a very low Young modulus (1 MPa) could be used.

Two examples of $\Delta R / R$ mapping are presented in Fig. 11, for a $50 \mu \mathrm{m}$ thick substrate. Fig. 11 (a) shows a 2D mapping between two consecutives scanning without pressure: resistances remain unchanged. The mean absolute resistance variation is $|\Delta R / R|=0.27 \%$, which proves a good stability. Fig. 11 (b) shows a 2D mapping for an applied static pressure of $\sim 1.9 \mathrm{~N} / \mathrm{mm}^{2}(190 \mathrm{~g})$. In both case, 800 resistors are measured. The relative variation $\Delta R / R$ increases on the stressed sensor, corresponding to a compression since the pressure is applied on the front face. Consequently, this sensor array is able to detect a pressure (or a deformation) on a single sensor. The spatial resolution used here, $500 \times 500 \mu \mathrm{m}^{2}$, is arbitrary and can be modified with respect to the applications aimed such as $200 \times 200 \mu \mathrm{m}^{2}, 100 \times 100 \mu \mathrm{m}^{2}$ and so on. 


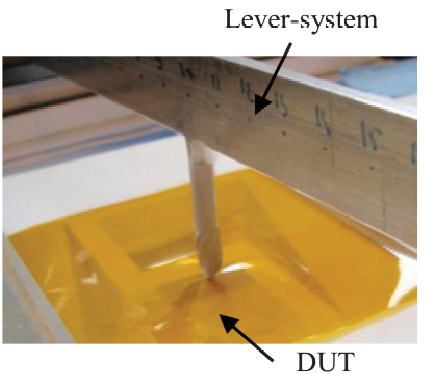

Additional weights

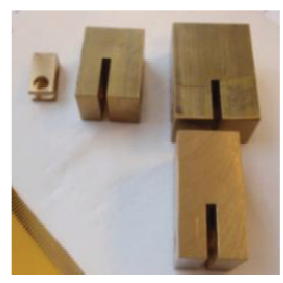

Fig. 10. Device Under Test (DUT) with custom pressure lever-system. The pressure is calculated considering a $1 \mathrm{~mm}^{2}$ contact surface and additional weights sliding on the lever $(8,108,170,200 \mathrm{~g})$.

(a) No pressure (flat)

(b) Pressure
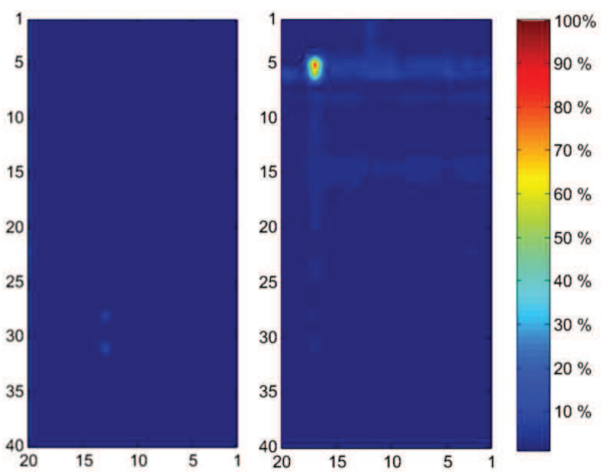

Fig. 11. 2D mapping of $\Delta R / R$ obtained for a $50 \mu \mathrm{m}$ thick substrate: (a) no pressure, (b) applied pressure (1.9 $\mathrm{N} / \mathrm{mm}^{2}$ ). A Matlab ${ }^{\circledR}$ interpolation algrorithm is used.

Fig. 12 summarizes the measurements made with various pressures on the 3 different substrate thicknesses $(25$, $50,125 \mu \mathrm{m})$. The maximum of $\Delta R / R$ is taken into account. Each value is the average of 3 maximum $\Delta R / R$ values. The data disparity can be explained by several points, mainly related to the custom lever-system: (i) the inhomogeneous pressure on the contact surface since the tip is spherical; (ii) due to the small size and the high spatial resolution, it is the difficult to define exactly where the pressure is applied: on a sensor, between 2 sensors or in the center of 4 sensors; (iii) the center of mass may vary between different tests, so the force direction varies in the same manner. Enhanced results would require a specific force instrument with a $(X, Y)$ movable chuck and a micrometer placement resolution, such as an indenter. We can notice that thinnest substrate permits to detect and measure lowest pressure. This result is consistent since a thin substrate ( $25 \mu \mathrm{m}$ thick) is easily deformable, resulting in a more sensitive sensor to low pressure. The response reaches a maximum easier to observe for the $25 \mu \mathrm{m}$ thick substrate than the two other thicknesses. This limitation is due to the local deformation, which is maximal. The high values can be explained by the small radius of the tip. Additional effects come from the process design. 


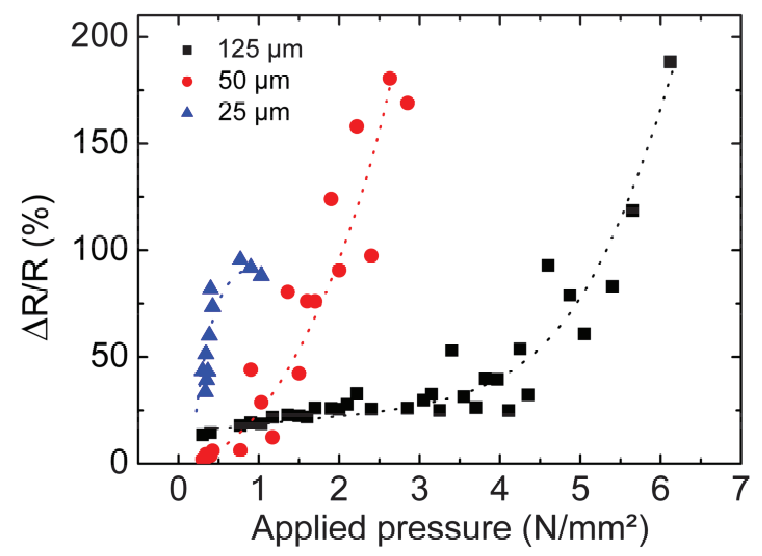

Fig. 12. $\Delta R / R$ peaks measured as a function of various applied pressures for 3 substrate thicknesses $(25,50,125$ $\mu \mathrm{m})$.

The detection of larger objects was also performed using a cylinder with a diameter of $\sim 1.5 \mathrm{~mm}$. Fig. 13 shows the cylinder applied on the middle (Fig. 13 (a)) or on the edge (Fig. 13 (b)) of the matrix and the response shows a good spatial localization. The inhomogeneous $\Delta R / R$ response observed is due to the surface roughness of the cylinder resulting in a deformation different from one point to another. This highlights the possibility to detect defects on the surface of materials with any shapes.

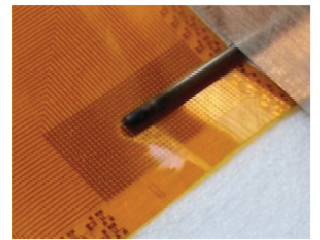

(a)

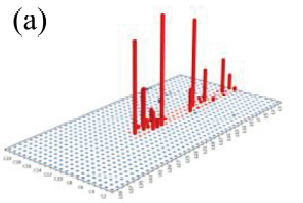

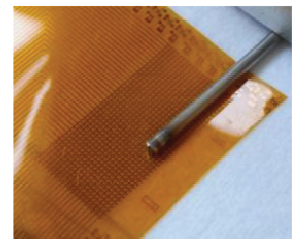

(b)

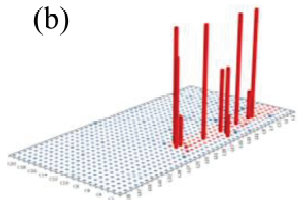

Fig. 13. Localisation of a cylinder with a diameter of $\sim 1.5 \mathrm{~mm}$ and the corresponding $\Delta R / R$ mapping responses: (a) in the middle of the matrix, (b) on the side of the matrix.

\section{Conclusion}

In conclusion, this paper has presented flexible strain sensor arrays on plastic using $n$-type doped microcrystalline silicon as piezoresistive element. The fabrication process is made at low temperature $\left(<200^{\circ} \mathrm{C}\right)$ and fit with various kind of plastics. Mechanical and electrical measurements showed good stability and high sensitivity. Indeed, microcrystalline silicon showed a longitudinal gauge factor of -31 and a longitudinal piezoresistive coefficient of $-4.10^{-10} \mathrm{~Pa}^{-1}$. Characterizations were made under tensile and compressive bending until radii of curvature down to $5 \mathrm{~mm}$ and no failure was observed. Sensor arrays with a high spatial resolution $\left(500 \times 500 \mu \mathrm{m}^{2}\right)$ have been processed on various substrate thicknesses $(25,50,125 \mu \mathrm{m})$ and showed excellent localisation of applied single pressure. Such matrix could be used for any applications demanding requirements in strain mapping on non-plane surface and limited spaces. This paper also showed that microcrystalline silicon can be a relevant semi-conductor for flexible electronic devices, thanks to the mature silicon technologies. 


\section{Acknowledgement}

This work was supported by ODAXOS SA and the French National Association for Research and Technology (ANRT) under the grant 2012/0307.

\section{References}

[1] T. Someya, Y. Kato, T. Sekitani, S. Iba, Y. Noguchi, Y. Murase, H. Kawaguchi, T. Sakurai, "Conformable, flexible, large-area networks of pressure and thermal sensors with organic transistor active matrixes" Proc. Nat. Acad. Sci. 102 (2005) 12321-12325

[2] S. Jung, T. Ji, V.K. Varadan, Point of care temperature and respiration monitoring sensors for smart fabric applications, Smart Mater. Struct. 15 (2006) 1872-1876

[3] D.H. Kim et Al., Epidermal electronics, Science 333838 (2011)

[4] R.B. Katragadda, Y. Xu, A novel intelligent textile technology based on silicon flexible skins, Sens. Actuators A 143 (2007) 169-174

[5] A. Casano, P. Capoluongo, S. Campopiano, A. Cutolo, M. Giordano, F. Felli, A. Paolozzi, M. Caponero, Experimental modal analysis of an aircraft model wing by embedded filter Bragg grating sensors, IEEE Sensors J. 6 (2006) 67-77

[6] S. Stassi, V. Cauda, G. Canavese, C.F. Pirri, Flexible Tactile Sensing Based on Piezoresistive Composites: A Review, Sensors 14 (2014) 5296-5332

[7] H. Yousefa, M. Boukallela, K. Althoefer, Tactile sensing for dexterous in-hand manipulation in robotics-A review, Sens. Actuators A 167 (2011) 171-187

[8] E. Fallettaa, P. Costab, C. Della Pinaa, S. Lanceros-Mendez, Development of high sensitive polyaniline based piezoresistive films by conventional and green chemistry approaches, Sens. Actuators A 220 (2014) $13-21$

[9] A. Bessonova, M. Kirikovaa, S. Haqueb, I. Gartseeva, M.J.A. Bailey, Highly reproducible printable graphite strain gauges for flexible devices, Sens. Actuators A 206 (2014) 75-80

[10] D. Lee, H.P. Hong, M.J. Lee, C.W. Park, N.K. Min, A prototype high sensitivity load cell using single walled carbon nanotube strain gauges, Sens. Actuators A 180 (2012) 120-126

[11] N. Lu, C. Lu, S. Yang, J. Rogers, Highly Sensitive Skin-Mountable Strain Gauges Based Entirely on Elastomers, Adv. Funct. Mater. 22 (2012) 4044-4050

[12] S. Yang, N. Lu, Gauge factor and stretchability of silicon-on-polymer strain gauges, Sensors 13 (7) (2013) $8577-8594$

[13] P.J. French, A.G.R. Evans, Piezoresistance in polysilicon and its applications to strain gauges, Solid State Electron. 32 (1) (1989) 1-10

[14] H. Gleskova, S. Wagner, W. Soboyejo, Z. Suo, Electrical response of amorphous silicon thin-film transistors under mechanical strain, J. Appl. Phys. 92 (2002) 6224-6229

[15] S.M. Won, H.S. Kim, N. Lu, D.G. Kim, C.D. Solar, T.A. Ameen, J.A. Rogers, "Piezoresistive strain sensors and multiplexed arrays using assemblies of single-crystalline silicon nanoribbons on plastic substrates", IEEE Electron. Dev. 58 (2011) 4074-4078

[16] K.H. Shina, C.R. Moona, T.H. Leeb, C.H. Limb, Y.J. Kimb, Flexible wireless pressure sensor module, Sens. Actuators A 123 (2005) 30-35

[17] C.F. Hu, H.Y. Huang, C.C. Wen, L.Y. Lin, W. Fang, Implementation of a Flexible Silicon-Based Tactile Sensor Array, IEEE Sensors Conference, pp. 1736-1739 (2010)

[18] L. Zhou, S. Jung, E. Brandon, T.N. Jackson, Flexible substrate micro-crystalline silicon and gated amorphous silicon strain sensors, IEEE Electron. Dev. 53 (2006) 380-385

[19] P. Alpuim, S.A. Filonovich, C.M. Costa, P.F. Rocha, M.I. Vasilevskiy, S. Lanceros-Mendez, C. Fria, A. Torres Marques, S. Roares, C. Costa, Fabrication of a strain sensor for bone implant failure detection based on piezoresistive doped nanocrystalline silicon, J. Non-Cryst. Sol. 354 (2008) 2585-2589

[20] P. Alpuim, V. Correia, E.S. Martins, J.G. Rocha, I.G. Trindade, S. Lanceros-Mendez, Piezoresistive silicon thin film sensor array for biomedical applications, Thin Solid Films 519 (2011) 4574-4577

[21] P. Alpuim, V. Chu, J.P. Conde, Piezoresistive sensors on plastic substrates using doped microcrystalline silicon, IEEE Sens. J. 2 (2002) 336-341

[22] P. Alpuim, J. Gaspar, P. Gieschke, C. Ehling, J. Kistner, N.J. Goncalves, M.I. Vasilevskiy, O. Paul, Study of the piezoresistivity of doped nanocrystalline silicon thin films, J. Appl. Phys. 109123717 (2011)

[23] A. Matsuda, Microcrystalline silicon. Growth and device application, J. Non-Cryst. Sol. 338 - 340 (2004) $1-12$

[24] K. Kandoussi, C. Simon, N. Coulon, K. Belarbi, T. Mohammed-Brahim, Nanocrystalline silicon TFT process using silane diluted in argon-hydrogen mixtures, J. Non Cryst. Sol. 354 (2008) 2513-2518 
[25] H. Gleskova, S. Wagner, Z. Suo, Failure resistance of amorphous silicon transistors under extreme in-plane strain, Appl. Phys. Lett. 75 (1999) 3011-3013

[26] Technical Data sheet, DuPont Kapton HN (available online)

[27] J. Gaspar, A. Gualdino, B. Lemke, O. Paul, V. Chu, J.P. Conde, Mechanical and piezoresistive properties of thin silicon films deposited by plasma-enhanced chemical vapor deposition and hot-wire chemical vapor deposition at low substrate temperatures, J. Appl. Phys. 112024906 (2012)

[28] Z. Suo, E.Y. Ma, H. Gleskova, S. Wagner, Mechanics of rollable and foldable film-on-foil electronics, Appl. Phys. Lett. 748 (1999) 1177-1179

[29] H.Y. Chang, S. Yang, J. Lee, L. Tao, W.S. Hwang, D. Jena, N. Lu, D. Akinwande, High-Performance, Highly Bendable MoS2 Transistors with High-K Dielectrics for Flexible Low-Power Systems, ACS Nano 7 (6) (2013) 5446-5452

[30] M. Shimojo, A. Namiki, M. Ishikawa, R. Makino, K. Mabuchi, A tactile sensor sheet using pressure conductive rubber with electrical-wires stitched method, IEEE Sens. J. 4 (5) (2004)

Yannick Kervran received his BS degree in Materials Science in 2009 at the University of Rennes 1 and his MS degree in Applied Science with a specialization on Nanotechnology Engineering in 2011, from a collaboration between the Ecole Centrale Paris and the University of Paris-Sud 11. He is currently pursuing the $\mathrm{PhD}$ degree in Electrical Engineering at the University of Rennes 1 . His research interests focus on medical devices and flexible electronics, which include materials, process strategies and packaging technologies. 